\title{
Comparative Analysis of Early versus Late Laparoscopic Cholecystectomy Following Endoscopic Retrograde Cholangiopancreaticography in Cases of Cholelithiasis with Choledocholithiasis
}

\author{
Apoorv Goel ${ }^{1}$, Shyam Kothari ${ }^{2}$, Roli Bansal ${ }^{3}$
}

\begin{abstract}
Introduction: A preferred treatment for cholelithiasis with choledocholithiasis is endoscopic retrograde cholangiopancreaticography (ERCP) followed by laparoscopic cholecystectomy (LC), which can be performed early (within 72 hours) or can be delayed for 6 to 8 weeks. This study is conducted to compare and analyze the outcome of early versus late LC following common bile duct (CBD) clearance by ERCP and determine the optimum timing for performing LC post-ERCP.

Materials and methods: This comparative analysis was conducted at St Joseph Hospital, Ghaziabad, from September 2019 to March 2021 on 89 cases of cholelithiasis with choledocholithiasis. Patients were divided into two groups. Group I $(n=45)$ patients underwent early LC within 72 hours post-ERCP and group II $(n=44)$ patients underwent late LC after an interval of 8 weeks. Various preoperative, perioperative, and postoperative clinical parameters like operative difficulty, complications, surgery duration, hospital stay, and conversion to open cholecystectomy were analyzed. Results: There was no significant difference in demographic and laboratory findings in both groups. Group I patients had significantly shorter hospital stay and less operative difficulty. The duration of surgery was significantly low in group I. There was no significant difference in rate of conversion to open cholecystectomy.

Conclusion: Early LC post-ERCP is associated with short hospital stay and duration of surgery and less operative difficulty and complications. Therefore, we recommend that LC can be safely performed within 48 to 72 hours after ERCP.

Keywords: Choledocholithiasis, Cholelithiasis, Endoscopic retrograde cholangiopancreaticography

Euroasian Journal of Hepato-Gastroenterology (2021): 10.5005/jp-journals-10018-1338
\end{abstract}

\section{INTRODUCTION}

Cholelithiasis is commonly seen in middle-aged females. Choledocholithiasis is defined as the presence of a stone in the common bile duct (CBD), and it often coexists with cholelithiasis. Laparoscopic cholecystectomy (LC) is the gold standard treatment for symptomatic cholelithiasis, and the preferred treatment for coexisting choledocholithiasis is endoscopic retrograde cholangiopancreaticography (ERCP) followed by LC. ${ }^{1-3}$ However, the debate on the timing of surgery post-ERCP is still on. Many studies had recommended early LC post-ERCP and others favor late LC after an interval of 6 to 8 weeks. Post-ERCP pancreatitis is not uncommon and is considered one of the relative contraindications for early LC. ${ }^{4-6}$ Many recent studies have shown that an interval of 6 to 8 weeks postERCP has shown increased operative difficulty as well as increased rate of conversion to open cholecystectomy. ${ }^{7-10}$ It is important to reduce morbidity and complications for the patients. The aim of this study was to compare and analyze the various parameters like operative difficulty, duration of surgery, hospital stay, complications, and conversion to open cholecystectomy among the patients undergoing LC immediately following the CBD stone extraction by ERCP with those undergoing LC after an interval of 8 weeks.

\section{Materials and Methods}

This study is a comparative analysis conducted at St Joseph Hospital, Ghaziabad, a tertiary care hospital, from September
1,2Department of General Surgery, St Joseph Hospital, Ghaziabad, Uttar Pradesh, India

${ }^{3}$ Department of Medicine, Division of Nephrology, UCMS \& GTB Hospital, New Delhi, India

Corresponding Author: Apoorv Goel, Department of General Surgery, St Joseph Hospital, Ghaziabad, Uttar Pradesh, India, e-mail: drapurvgoel@gmail.com

How to cite this article: Goel A, Kothari S, Bansal R. Comparative Analysis of Early versus Late Laparoscopic Cholecystectomy Following Endoscopic Retrograde Cholangiopancreaticography in Cases of Cholelithiasis with Choledocholithiasis. Euroasian J HepatoGastroenterol 2021;11(1):11-13.

Source of support: Nil

Conflict of interest: None

2019 to March 2021. During this period, around 105 patients with choledocholithiasis were seen and 89 out of them were enrolled for the study. All patients above 18 years of age suffering from cholelithiasis and choledocholithiasis were included in the study. Patients with severe cardiorespiratory illness, acute cholangitis, multiorgan failure, acute kidney injury, post-ERCP pancreatitis, jaundice (S. bilirubin $>2.5$ ), biliary injury post-ERCP, and malignancy were excluded from the study. Enrolled participants were divided into two groups: group I $(n=45)$ underwent LC within 48 hours

(C) The Author(s). 2021 Open Access This article is distributed under the terms of the Creative Commons Attribution 4.0 International License (https://creativecommons. org/licenses/by-nc/4.0/), which permits unrestricted use, distribution, and non-commercial reproduction in any medium, provided you give appropriate credit to the original author(s) and the source, provide a link to the Creative Commons license, and indicate if changes were made. The Creative Commons Public Domain Dedication waiver (http://creativecommons.org/publicdomain/zero/1.0/) applies to the data made available in this article, unless otherwise stated. 
prior to ERCP in the same hospitalization and group II $(n=44)$ underwent LC after an interval of 8 weeks. Various preoperative and intraoperative parameters were analyzed. The two groups were compared statistically in terms of gender, age, body mass index (BMI), operation time, adhesion level (grade), operative difficulty, postoperative length of hospital stay, conversion rate to open surgery, biliary duct injury, deep and superficial site infections, and other factors. Severity of adhesions was based on a scoring system based on the study by Ercan et al. 6 and operative difficulty scoring (Table 1) was based on the study by Sugrue et al. ${ }^{7}$

All patients of choledocholithiasis underwent ERCP with CBD stenting followed by the standard four-port LC. A complete hemogram, liver function test, and serum amylase/lipase were repeated 24 hours prior to the surgery. Laparoscopic cholecystectomy was done under general anesthesia by the same team of surgeons with more than 10 years of experience in laparoscopic surgery.

Statistical analysis was performed using SPSS (Statistical Package for the Social Sciences) for Windows (version 24.0). Categorical variables were described as frequency (percentage); mean \pm standard deviation was used for continuous parameters. Differences between the two groups were compared by the Student's t-test. For all analyses, a two-tailed $p$-value of $<0.05$ was considered statistically significant.

\section{Observation and Results}

A total of 89 patients were enrolled in this study, of which 71 females and 18 males were there. Mean age was $45 \pm 1.23$ and $43 \pm 0.93$ in group I and group II, respectively. There was no significant difference in BMI and other comorbid conditions in both the groups. On ultrasonography (USG), pericholecystic edema was seen significantly more in group I and increased wall thickness was seen more in group II. Mean duration of surgery was significantly

Table 1: Operative grading system for cholecystitis severity

\begin{tabular}{ll}
\hline Gallbladder (GB) appearance & \\
\hline Adhesions $<50 \%$ of GB & 1 \\
Adhesions burying GB & Max 3 \\
Distension/contraction & 1 \\
Distended GB (or contracted shriveled GB) & 1 \\
Unable to grasp with atraumatic laparoscopic forceps & 1 \\
Stone $\geq 1$ cm impacted in Hartmann's pouch & 1 \\
Access & \\
BMI $>30$ & 1 \\
Adhesions from previous surgery limiting access & 1 \\
Severe sepsis/complications & \\
Bile or pus outside GB & 1 \\
Time to identify cystic artery and duct $>90$ min & 1 \\
Degree of difficulty & Total Max 10 \\
$\quad$ A. Mild & \\
B. Moderate & $<2$ \\
C. Severe & $2-4$ \\
D. Extreme & $5-7$ \\
& $8-10$ \\
\hline
\end{tabular}

higher in patients undergoing surgery later. The length of hospital stay was significantly reduced for group I (Table 2).

It was observed that group II patients had more severe adhesions during surgery as compared to group I in which only mild adhesions were noticed. Even operative difficulty grade and cholecystitis severity score were significantly high for patients in group II. The majority of the cases in group II had severe score, whereas in group I, the score was mild and moderate. The requirement of the drain was seen more in group II cases. There was no difference in bile duct injury, conversion to open cholecystectomy, laparoscopic subtotal cholecystectomy, bleeding, wound infection, and readmission between both the groups (Table 3 ).

\section{Discussion}

Cholelithiasis and choledocholithiasis are seen more frequently in middle-aged females. It has been a matter of debate and discussion about the timing of LC after ERCP and CBD stone extraction. In this study, there was no significant difference seen among demographic findings that correlate with the previous studies., ${ }^{9,10}$ However, significant preoperative ultrasound finding was increased wall thickness in group II. ${ }^{10}$ It was clearly observed that and seen consistent with our studies that the duration of surgery and hospital stay was significantly more in patients undergoing LC after an interval of 8 weeks. ${ }^{9-11}$ Operative difficulty and grade of adhesions were significantly higher in cases undergoing surgery after a delayed period, and this observation is clearly supported by many studies. ${ }^{8-11}$ Many studies have shown a significant difference in conversion to open cholecystectomy, but in our study, however,

Table 2: Characteristics of the patients

\begin{tabular}{|c|c|c|c|}
\hline & $\begin{array}{l}\text { Group I } \\
(n=45)\end{array}$ & $\begin{array}{l}\text { Group II } \\
(n=44)\end{array}$ & $p$-value \\
\hline Age (years) & $45 \pm 1.23$ & $43 \pm 0.93$ & 0.78 \\
\hline \multicolumn{4}{|l|}{ Sex } \\
\hline Male & $10(22.22 \%)$ & $8(18.18 \%)$ & 0.93 \\
\hline Female & $35(77.78 \%)$ & $36(81.82 \%)$ & 0.87 \\
\hline BMI $\left(\mathrm{kg} / \mathrm{m}^{2}\right)$ & $25 \pm 0.53$ & $24 \pm 0.67$ & 0.76 \\
\hline HT & $7(15.55 \%)$ & $8(18.18 \%)$ & 1.01 \\
\hline DM & $8(17.77 \%)$ & $10(22.72 \%)$ & 0.98 \\
\hline CAD & $1(2.22 \%)$ & $2(4.57 \%)$ & 1.23 \\
\hline COPD & $2(4.44 \%)$ & $1(2.27 \%)$ & 1.11 \\
\hline $\begin{array}{l}\text { Preop laparotomy/ } \\
\text { laparoscopy }\end{array}$ & $2(4.44 \%)$ & $2(4.57 \%)$ & 1.21 \\
\hline $\begin{array}{l}\text { Preop gallbladder USG } \\
\text { Pericholecystic edema }\end{array}$ & & & \\
\hline Increased wall thickness & $5(11.11 \%)$ & 1 (2.27\%) & 0.03 \\
\hline Mucocele gallbladder & $\begin{array}{r}10(22.5 \%) \\
4(8.88 \%)\end{array}$ & $\begin{array}{l}25(56.81 \%) \\
2(4.57 \%)\end{array}$ & $\begin{array}{l}0.02 \\
0.76\end{array}$ \\
\hline $\begin{array}{l}\text { Post-ERCP } \\
\text { pancreatitis/recurrent } \\
\text { biliary }\end{array}$ & & & \\
\hline symptoms & $3(6.67)$ & $5(11.56)$ & 0.78 \\
\hline Duration of surgery (min) & $55 \pm 3.56$ & $78 \pm 2.45$ & 0.002 \\
\hline Hospitalization (days) & $2.8 \pm 0.57$ & $4.2 \pm 1.01$ & 0.011 \\
\hline
\end{tabular}

$\mathrm{BMI}$, body mass index; $\mathrm{HT}$, hypertension; DM, diabetes mellitus; CAD, coronary artery disease; COPD, chronic obstructive pulmonary disease; preop, preoperative; USG, ultrasonography 
Table 3: Intraoperative and postoperative factors

\begin{tabular}{|c|c|c|c|}
\hline & $\begin{array}{l}\text { Early group } \\
(n=45)\end{array}$ & $\begin{array}{l}\text { Delayed } \\
\text { group } \\
(n=44)\end{array}$ & $p$-value \\
\hline \multicolumn{4}{|l|}{ Intraoperative adhesion } \\
\hline grade 1 & $4(8.88 \%)$ & $2(4.54 \%)$ & 0.77 \\
\hline grade 2 & $28(62.22 \%)$ & $10(22.72 \%)$ & 0.002 \\
\hline grade 3 & $8(17.78 \%)$ & $20(45.46 \%)$ & 0.012 \\
\hline grade 4 & $5(11.11 \%)$ & $12(27.27 \%)$ & 0.023 \\
\hline \multicolumn{4}{|l|}{$\begin{array}{l}\text { Intraoperative grading and } \\
\text { cholecystitis severity score } \\
\text { (out of 10) }\end{array}$} \\
\hline $\operatorname{Mild}(<2)$ & $23(51.11 \%)$ & $8(18.18 \%)$ & 0.002 \\
\hline Moderate (2-4) & $15(33.33 \%)$ & $10(22.73 \%)$ & 0.54 \\
\hline Severe (5-7) & $6(13.33 \%)$ & $21(47.73 \%)$ & 0.001 \\
\hline Extreme $(8-10)$ & $1(2.22 \%)$ & $5(11.36 \%)$ & 0.034 \\
\hline $\begin{array}{l}\text { Conversion to open } \\
\text { cholecystectomy }\end{array}$ & $2(4.44 \%)$ & $3(6.82 \%)$ & 0.76 \\
\hline $\begin{array}{l}\text { Laparoscopic subtotal } \\
\text { cholecystectomy }\end{array}$ & $2(4.44 \%)$ & $4(9.10 \%)$ & 0.65 \\
\hline Biliary tract injury & $1(2.22 \%)$ & $2(4.54 \%)$ & 0.88 \\
\hline $\begin{array}{l}\text { Bleeding requiring blood } \\
\text { transfusion }\end{array}$ & 0 & $1(2.27 \%)$ & 0.70 \\
\hline Drain placement & $13(28.89 \%)$ & $24(54.55 \%)$ & 0.041 \\
\hline $\begin{array}{l}\text { Superficial wound } \\
\text { infection }\end{array}$ & $1(2.22 \%)$ & $2(4.54 \%)$ & 0.98 \\
\hline Deep wound infection & 0 & $1(2.27 \%)$ & 0.72 \\
\hline Hospital readmission & $1(2.22 \%)$ & $2(4.54 \%)$ & 0.84 \\
\hline
\end{tabular}

cases of conversion were more in delayed group but statistically insignificant. ${ }^{9,10}$

Many studies have supported early LC post-ERCP. On the same day, LC post-ERCP and simultaneous laparoendoscopic management are also being popularized. ${ }^{12-14}$ We too suggest that LC performed early within 48 hours post-ERCP is beneficial in terms of surgery duration, hospital stay, and operative difficulty.

\section{Conclusion}

Early LC performed within 48 to 72 hours post-ERCP is associated with shorter hospital stay, less operative difficulty, and shorter duration of surgery. Results are consistent with lesser complications and morbidity. Therefore, it is recommended to go for early LC post-ERCP in the cases of choledocholithiasis.

\section{Acknowledgments}

The protocol for this study was approved by the Ethical Committee of the institute. This research did not receive any specific grant from funding agencies in the public, commercial, or not-for-profit sectors. There is no conflict of interests to be declared.

\section{References}

1. Schirmer BD, Edge SB, Dix J, et al. Laparoscopic cholecystectomy. Treatment of choice for symptomatic cholelithiasis. Ann Surg 1991;213:665-676. DOI: 10.1097/00000658-199106000-00018.

2. Reinders JSK, Gouma DJ, Heisterkamp J, et al. Laparoscopic cholecystectomy is more difficult after a previous endoscopic retrograde cholangiography. HPB 2013;15:230-234. DOI: 10.1111/j.1477-2574.2012.00582.x.

3. Phillips MS, Marks JM. Endoscopic retrograde cholangiopancreatography: general principles. SAGES Man 2012;2012:411-425. Available at: https://www.sages.org/publications/ patient-information/patient-information-for-ercp-endoscopicretrograde-cholangio-pancreatography-from-sages/

4. Mann K, Belgaumkar AP, Singh S. Post-endoscopic retrograde cholangiography laparoscopic cholecystectomy: challenging but safe. JSLS 2013;17:371-375. DOI: 10.4293/108680813X13654754535511.

5. Salman B, Yilmaz $U$, Kerem $M$, et al. The timing of laparoscopic cholecystectomy after endoscopic retrograde cholangiopancreaticography in cholelithiasis coexisting with choledocholithiasis. J Hepatobiliary Pancreat Surg 2009;16:832-836. DOI: 10.1007/s00534-009-0169-4.

6. Ercan M, Bostancı EB, Teke Z, et al. Predictive factors for conversion to open surgery in patients undergoing elective laparoscopic cholecystectomy. J Laparoendosc Adv Surg Tech A 2010;20:427-434. DOI: 10.1089/lap.2009.0457.

7. Sugrue M, Sahebally SM, Ansaloni L, et al. Grading operative findings at laparoscopic cholecystectomy- a new scoring system. World J Emerg Surg 2015;10:14. DOI: 10.1186/s13017-015-0005-x.

8. Sahu D, Mathew MJ, Reddy PK. Outcome in patients undergoing laparoscopic cholecystectomy following ERCP; Does timing of surgery really matter? J Minim Invasive Surg Sci 2015;4:e25226. Available at: https://sites.kowsarpub.com/minsurgery/articles/17816.html

9. Aziret M, Karaman K, Ercan M, et al. Early laparoscopic cholecystectomy is associated with less risk of complications after the removal of common bile duct stones by endoscopic retrograde cholangiopancreatography. Turk J Gastroenterol 2019;30(4):336-344. DOI: 10.5152/tjg.2018.18272.

10. Sahoo R, Samal D, Pradhan A, et al. Optimal timing of laparoscopic cholecystectomy after endoscopic retrograde cholangiopancreatography. Int Surg J 2017;4:3504-3506. DOI: 10.18203/2349-2902.isj20174101.

11. Friis C, Rothman JP, Burcharth J, et al. Optimal timing for laparoscopic cholecystectomy after endoscopic retrograde cholangiopancreatography: a systematic review. Scand J Surg 2018;107(2):99-106. DOI: 10.1177/1457496917748224.

12. Morino M, Baracchi F, Miglietta C, et al. Preoperative endoscopic sphincterotomy versus laparoendoscopic rendezvous in patients with gallbladder and bile duct stones. Ann Surg 2006;244:889-896. DOI: 10.1097/01.sla.0000246913.74870.fc.

13. Akaraviputh $T$, Rattanapan $T$, Lohsiriwat $V$, et al. A same day approach for choledocholithiasis using endoscopic stone removal followed by laparoscopic cholecystectomy: a retrospective study. J Med Assoc Thai 2009;92(1):8-11. Available at: https://pubmed.ncbi.nlm.nih. gov/19260236/

14. Zang J, Zhang C, Zhou H. Early laparoscopic cholecystectomy after endoscopic common bile duct stone extraction: the experience from a developing country. Surg Laparosc Endosc Percutan Tech 2011;21(2):120-122. DOI: 10.1097/SLE.0b013e318213c7b8. 